\title{
Effect of genetic and nongenetic factors on chemical composition of individual milk samples from dromedary camels (Camelus dromedarius) under intensive management
}

\author{
P. Nagy, ${ }^{* 1}$ Zs. N. Fábri, $†$ L. Varga, $†$ J. Reiczigel, $\ddagger$ and J. Juhász* \\ *Emirates Industry for Camel Milk and Products, Farm and Veterinary Department, PO Box 294236, Dubai, United Arab Emirates \\ †Department of Food Science, Faculty of Agricultural and Food Sciences, Széchenyi István University, 9200 Mosonmagyaróvár, Hungary \\ ‡Department of Biomathematics and Informatics, University of Veterinary Medicine, 1078 Budapest, Hungary
}

\begin{abstract}
The aims of the present study were to monitor the changes in gross chemical composition of individual dromedary camel milk over a 5-yr period, to provide reference values, and to determine the effect of genetic and nongenetic factors influencing camel milk composition under intensive management. A total of 1,528 lactating dromedary camels were included in the study. Animals were fed a constant diet and were milked twice a day in a herringbone parlor. Milk samples were collected at monthly intervals using a sampling device and then fat, protein, lactose, total solids (TS), and solids-nonfat (SNF) concentrations of raw camel milk were determined with an automatic milk analyzer. For each milk sample, production parameters were recorded and quantities (grams) of milk constituents were calculated. The overall mean quantity and fat, protein, lactose, SNF, and TS concentrations of the morning milk were $4.0 \mathrm{~kg}, 2.58 \%, 2.95 \%, 4.19 \%, 8.08 \%$, and $10.46 \%$, respectively. Milk quantity showed a positive correlation with lactose and a negative correlation with all other components. Parity exerted a strong effect on all milk parameters. Primiparous dromedaries $(\mathrm{n}=$ 60) produced less milk with higher concentrations of components than did multiparous animals $(\mathrm{n}=1,468)$. Milk composition varied among the 7 breeds tested, but none of the genotypes was found to be superior to the others in this respect. We detected a significant, yet small calf sex-biased difference in milk yield and composition. Stage of lactation and season strongly influenced milk yield and all milk components. We also found a significant interaction between month postpartum $(\mathrm{mPP})$ and month of the year. The concentration of all milk components decreased from 1 to $5 \mathrm{mPP}$. Later, lactose concentration and quantity continued to
\end{abstract}

Received March 1, 2017.

Accepted July 16, 2017.

${ }^{1}$ Corresponding author: peter@camelicious.ae decrease parallel with decreasing milk production. The concentration of other components showed a temporary increase in midlactation, from 6 to $11 \mathrm{mPP}$, and in late lactation, from 18 to $23 \mathrm{mPP}$. Mean fat, protein, $\mathrm{SNF}$, and TS concentrations showed a high seasonal variation (9.5 to $28.7 \%$ ), with the lowest and highest values being measured during summer and winter, respectively. This seasonal variation was independent of nutrition and may reflect an endogenous circannual rhythm. We observed a noticeable variation among years. Dromedary camels could provide a useful in vivo model to study the homeorhetic regulation of mammary cell function by endogenous and environmental factors.

Key words: dromedary camel, milk composition, season, stage of lactation

\section{INTRODUCTION}

The world's annual camel milk production increased from 0.63 million tonnes in 1961 to $\sim 2.9$ million tonnes in 2013 (FAO, 2017); this is a 4.6-fold increase in production over a 50-yr period. With this quantity, camels are the fifth most important dairy animals, following cattle, water buffalo, goat, and sheep (Faye and Bonnet, 2012). However, most of the production is consumed locally, without further processing, and, therefore, camel milk has not yet been widely integrated into national and international markets. This situation is likely to improve in the next decade because of the ongoing development of the camel dairy industry that started 10 to 15 yr ago (Nagy and Juhász, 2016). Machine milking has been introduced in several traditional camelkeeping countries (e.g., Tunisia, Saudi Arabia, and the United Arab Emirates). Small-scale farms in Australia, Europe, and the United States have also started using milking machines for dromedaries. As a result, more and more raw milk is processed and new camel milkbased products are developed and marketed worldwide (Varga et al., 2014).

Due to this increase in camel milk processing, it is essential that the physicochemical composition of raw 
camel milk be regularly monitored so that the role of various factors influencing milk composition and processing characteristics can be fully understood. Although the composition of dromedary camel milk was described in many previous publications and has recently been summarized by several authors (Konuspayeva et al., 2009; Al haj and Al Kanhal, 2010; Fábri et al., 2014), systematic, long-term studies have not yet been conducted on this species. Mean dromedary camel milk fat, protein, lactose, and TS contents were reported to be 3.5 to 3.8 , 3.1 to $3.35,4.4$ to 4.57 , and 11.9 to $12.47 \%$, respectively (Konuspayeva et al., 2009; Al haj and Al Kanhal, 2010). However, literature data show a wide range of variation, and the results of different studies are difficult to compare because of the differences in environmental and physiological conditions, breed, year, and methodology. In most studies, few samples were taken only a single time from a low number of individual animals, and the experimental conditions are insufficiently described (Elamin and Wilcox, 1992; Guliye et al., 2000; Al-Sultan and Mohammed, 2007; Ahmad et al., 2012). Longitudinal studies involving repeated sampling from the same animals throughout a lactation period have been scarce (Bakheit et al., 2008; Konuspayeva et al., 2010; Al-Saiady et al., 2012; Musaad et al., 2013). Even fewer reports are available on the composition of bulk or pooled camel milk (Kouniba et al., 2005, Haddadin et al., 2008).

Previous works have found breed (Mehaia et al., 1995; Aljumaah et al., 2012), stage of lactation (Zeleke, 2007; Musaad et al., 2013), parity (Zeleke, 2007; Aljumaah et al.; 2012), season (Haddadin et al., 2008; Shuiep et al., 2008), management or production system (Shuiep et al., 2008; Aljumaah et al., 2012), feeding (Abdoun et al.; 2007; Al-Saiady et al.; 2012), geographical location, and year (Konuspayeva et al., 2009) to be major factors influencing the composition of dromedary camel milk. However, the number of observations in most studies is rather limited. This may be one of the reasons for the sometimes conflicting results.

Changes in composition of raw milk and its relationship with processing characteristics, such as cheese yield and quality, have been extensively studied in major dairy animal species (Barron et al., 2001; Fekadu et al., 2005; Chen et al., 2014). Milk composition varies considerably among countries and from year to year (Heck et al., 2009; Schönfeldt et al., 2012; Chen et al., 2014). In addition, a significant seasonal variation in main milk components has been demonstrated by multiple studies in bovine, caprine, and ovine milk (Barron et al., 2001; Fekadu et al., 2005; Heck et al., 2009; Chen et al., 2014). These seasonal changes have been attributed to stage of lactation, nutritional factors, or both, and have a major effect on the quality of final products. The objectives of our study were (1) to monitor the chemical composition of regularly collected individual milk samples over several years at the world's first large-scale dairy camel farm, (2) to provide solid reference values for dromedary camel milk composition, and (3) to determine the most important genetic and nongenetic factors affecting milk composition under intensive management.

\section{MATERIALS AND METHODS}

\section{Dromedaries, Management of the Farm, and Milking of the Animals}

The study was conducted at the premises of Emirates Industry for Camel Milk and Products, the world's first large-scale dairy camel farm located in Dubai, United Arab Emirates $\left(25^{\circ} \mathrm{N}, 55^{\circ} \mathrm{E}\right)$, from May 2009 through December 2013. A total of 1,528 lactating dromedary camels were included in the study, and the number of animals milked daily ranged from 421 to 828 during this time. The animals belonging to different breeds or ecotypes were between 5 to 19 yr of age and had variable parity. Dromedaries were kept in groups of 12 or 24 animals in open paddocks. Calves were weaned partially and were kept in adjacent paddocks next to their dams throughout lactation. They were allowed to suckle after each milking. The normal daily ration consisted of 5 to $6 \mathrm{~kg}$ of wheat bran and 6 to $7 \mathrm{~kg}$ of alfalfa hay $(15 \% \quad \mathrm{CP})$ distributed with feeding wagons as TMR in 2 portions per day throughout the year. Further details of farm management have been described elsewhere (Nagy et al., 2013a,b).

Dromedaries were milked twice a day with an automatic system in a $2 \times 12$ herringbone milking parlor. Milk yield $(\mathrm{kg})$ of individual dromedaries was measured during each milking with a milk meter approved by the International Committee for Animal Recording (ICAR). Data were collected by herd management software (Nagy et al., 2013a,b). Machine milking started 30 to $40 \mathrm{~d}$ after parturition, when the calves were mature enough to cope with partial separation and dry feed intake. In case of calf mortality within 1 mo after parturition, machine milking was started immediately to maintain the lactation of the dam. Further details of the milking routine have been described in previous papers (Nagy et al., 2013a,b).

\section{Sample Collection and Laboratory Analysis}

As part of the herd health and milk quality-monitoring program, milk samples from individual dromedar- 
ies were collected approximately at monthly intervals during lactation. According to the monthly schedule, each weekday a group of 12 to 24 dromedary camels kept in the same paddock was selected for sampling. Milk samples were taken in the morning milking session during milk letdown using removable sampling bottles mounted into the milking line after the outlet port of the ICAR-approved milk meter (ICAR, 2017). Such a milk sampling device enables collection of representative milk samples of sufficient quantity (i.e., $>20 \mathrm{~cm}^{3}$ ) from all stages of the milking session for the determination of chemical composition (Kamphuis et al., 2015). Upon completion of milking, each sample was transferred from the collection bottle to a $60-\mathrm{cm}^{3}$ sample container. All samples were kept refrigerated at $4^{\circ} \mathrm{C}$ until being transferred to the on-site laboratory for immediate analysis.

The gross chemical composition (i.e., fat, protein, lactose, TS, and SNF concentrations) of raw camel milk was determined with an automatic milk analyzer (MilkoScan FT 120; Foss A/S, Hillerød, Denmark). The equipment has been validated against reference methods by the manufacturer and has also been calibrated for raw camel milk (Nagy et al., 2013b). Aliquots of raw camel milk were collected every 2 to 3 wk from the bulk tank for controls. These aliquots were preserved with acidiol ( $3 \mu \mathrm{L} / \mathrm{mL}$; Merck, Darmstadt, Germany) and were kept at $4^{\circ} \mathrm{C}$ until testing. Repeatability was monitored by measuring the control samples 5 times on each test day. From these data, inter- and intratest day coefficients of variation were calculated. The inter- and the intra-test day coefficients of variation throughout the study for the different parameters were ranging from 0.32 to $0.61 \%$ and from 0.31 to $0.65 \%$, respectively.

\section{Collection of Production Parameters, Breeds or Ecotypes, and Statistical Analysis}

The following parameters were recorded for each milk sample: animal, date, year, month of the year, days postpartum (dPP) and month postpartum ( $\mathbf{m P P})$, parity, breed or ecotype, calf sex, and daily morning milk yield $(\mathrm{kg})$. The $\mathrm{mPP}$ was calculated from $\mathrm{dPP}$ using the formula $\mathrm{mPP}=\operatorname{round}(\mathrm{dPP} / 30+0.49)$. Due to lack of complete history, parity was defined as either first delivery (primiparous) or more than 1 deliveries (multiparous). Based on geographical origin, color, appearance, and body conformation, dromedaries were categorized into the following well-distinguishable breeds or ecotypes: Emirati, Emirati-cross, Black, Pakistani, Saudi, Saudi-cross, and Sudanese. Using gross chemical composition and morning milk yield data, the fat, protein, lactose, SNF, and TS quantities (grams) produced during each milking were also calculated and used for further analysis.

The effects of parity, breed or ecotype, calf sex, stage of lactation (mPP), season (month of the year), and year were tested by $t$-test and linear models with Tukey's test for pairwise comparisons using the $\mathrm{R}$ statistical package $[\mathrm{R}$ version 3.3.3 (2016-10-31), $\mathrm{R}$ Foundation for Statistical Computing, Vienna, Austria]. Due to the uneven distribution of samples, these effects were tested on different subsets of data. Association between milk yield and milk composition parameters was evaluated by Pearson correlation.

The effect of parity was evaluated by $t$-test, and then the samples of primiparous dromedaries were excluded from further analysis. Breed effect was tested on several subsets of data, but only the analysis on data from 2013 is presented. In that particular year, samples were collected from all 7 ecotypes and the linear mixed model included breed or ecotype, month, and breed $\times$ month interaction as fixed factors and $\mathrm{mPP}$ as a random factor. The effects of season (month of the year), stage of lactation $(\mathrm{mPP})$, season $\times$ stage of lactation, and sex were tested by mixed linear model with breed and year as random factors. The model included all samples collected from multiparous animals throughout the study. The effect of year was evaluated by a linear mixed model including 4 breeds or ecotypes that occurred in each study year (Emirati, Emiraticross, Saudi, and Saudi-cross), with month and mPP as random factors.

\section{RESULTS}

\section{Overall Descriptive Statistics and Correlation Between Milk Components}

During the study, a total of 18,158 milk samples were collected on 963 test days. Samples with incomplete production parameters or from milk yield below $1 \mathrm{~kg}$ were omitted. Therefore, 16,851 samples taken on 955 test days (mean $\pm \mathrm{SD} ; 17.6 \pm 8.1$ samples/d) from 1,528 dromedaries $(11.0 \pm 6.8$ samples/animal $)$ were included in the final analysis. The vast majority of samples $(98.1 \%, \mathrm{n}=16,533)$ originated from 1,468 dromedaries with 2 or more deliveries, whereas 318 samples (1.9\%) from 60 primiparous animals were also available. Of the multiparous dromedaries, 434 and 13 animals (29.6 and 0.9\%) contributed samples for 2 and 3 lactations, respectively. The yearly distribution of samples included in the final analysis is shown in Table 1, and the numbers of dromedaries per breed or ecotype and parity are detailed in Table 2. The overall mean $( \pm$ SEM $)$ daily yield and fat, protein, lactose, SNF, and TS concentrations of the morning milk 
Table 1. Yearly distribution of milk samples according to breed or ecotype and parity (primiparous + multiparous) of dromedaries

\begin{tabular}{|c|c|c|c|c|c|c|c|c|c|}
\hline Year & \multicolumn{9}{|c|}{ Breed or ecotype } \\
\hline 2010 & $0+1,043$ & $0+385$ & $0+87$ & $0+0$ & $0+994$ & $0+1,296$ & $0+481$ & $0+19$ & $0+4,305$ \\
\hline 2011 & $5+994$ & $4+678$ & $0+145$ & $0+1$ & $12+709$ & $0+1,025$ & $0+440$ & $0+3$ & $21+3,995$ \\
\hline 2012 & $10+550$ & $9+564$ & $0+92$ & $0+70$ & $18+483$ & $4+400$ & $0+193$ & $0+8$ & $41+2,360$ \\
\hline
\end{tabular}

were $4.00 \pm 0.012 \mathrm{~kg}, 2.58 \pm 0.007 \%, 2.95 \pm 0.004 \%$, $4.19 \pm 0.004 \%, 8.08 \pm 0.006 \%$, and $10.46 \pm 0.01 \%$, respectively, throughout the study. The daily mean $( \pm \mathrm{SEM})$ fat, protein, lactose, SNF, and TS contents of the morning milk were $99.7 \pm 0.33,116.1 \pm 0.33,168.4$ $\pm 0.53,321.7 \pm 0.94$, and $413.9 \pm 1.18 \mathrm{~g}$, respectively (Table 3 ). Table 4 indicates that all major chemical components (\%) and the daily yield (kg) of morning milk were highly correlated $(P<0.001)$. Morning milk yield $(\mathrm{kg} / \mathrm{d})$ showed a positive correlation with lactose (\%) and a negative correlation with all other components tested. Fat and lactose percentages correlated negatively with each other; however, the relationship between any other pairs of milk components was positive (Table 4).

\section{Effect of Parity}

The number and percentage of milk samples $(\mathrm{n}=318$; $1.9 \%)$ from primiparous animals $(\mathrm{n}=60 ; 3.9 \%)$ was low compared with those from multiparous dromedary camels. In addition, the majority of samples from primiparous dromedaries $(\mathrm{n}=256 ; 80.5 \%)$ were collected during the final year of the study and breeds or ecotypes were represented disproportionately (Tables 1 and 2). For these reasons, the influence of various factors was only tested on samples from multiparous dromedaries. Despite the uneven distribution of samples, parity exerted a strong effect $(P<0.001)$ on all morning milk parameters tested. Primiparous animals produced less milk with reduced quantities of fat, protein, lactose, SNF, and TS than did their multiparous counterparts $(P<0.001$, Table 3$)$. However, in terms of chemical composition (i.e., percentages of major chemical components), the milk from primiparous dromedary camels was superior to that from multiparous dromedaries $(P$ $<0.001$, Table 3).

\section{Effect of Breed}

The effect of breed or ecotype was evaluated on several subsets of data, but only results from 2013 are presented. In that particular year, all 7 genotypes contributed and a total of 2,332 milk samples were collected from multiparous dromedaries with a known parturition date. Almost $90 \%$ of the samples $(\mathrm{n}=2,090$; $89.6 \%$ ) originated from 4 ecotypes (Emirati, Emiraticross, Saudi, and Saudi-cross), whereas the rest $(\mathrm{n}=$ $242 ; 10.4 \%$ ) were provided by the other 3 breeds or ecotypes. As shown in Figure 1, breed or ecotype had a strong influence on all parameters $(P<0.01$ for fat percentage and $P<0.001$ for all other parameters tested). The effect of month of the year was also confirmed; however, no interaction was found between the 2 factors. The stage of lactation was different among breeds or ecotypes $(P<0.05)$. Mean $( \pm \mathrm{SEM}) \mathrm{dPP}$ of Emirati, Emirati-cross, Black, Pakistani, Saudi, Saudi-cross, and Sudanese camels were $298 \pm 6.7,324 \pm 8.8,371 \pm 19.6$, $496 \pm 13.4,325 \pm 6.7,249 \pm 5.1$, and $316 \pm 12.8 \mathrm{~d}$, respectively.

Table 2. Breed or ecotype and parity of dromedaries included in this study

\begin{tabular}{lcccc}
\hline Breed or ecotype & Primiparous (no.) & Multiparous (no.) & Total (no.) & Percentage of genotype \\
\hline Emirati & 22 & 332 & 354 & 23.2 \\
Emirati-cross & 8 & 242 & 250 & 16.3 \\
Black & 1 & 49 & 50 & 3.3 \\
Pakistani & 0 & 89 & 89 & 5.8 \\
Saudi & 23 & 290 & 313 & 20.5 \\
Saudi-cross & 6 & 300 & 306 & 20.0 \\
Sudanese & 0 & 136 & 136 & 8.9 \\
Unknown & 0 & 30 & 30 & 2.0 \\
Total & 60 & 1,468 & 1,528 & 100.0 \\
\hline
\end{tabular}


Table 3. Influence of parity on daily yield, chemical composition, and quantity of major components of morning dromedary camel milk (mean \pm SEM)

\begin{tabular}{lccc}
\hline Parameter & $\begin{array}{c}\text { Primiparous } \\
(\mathrm{n}=318)\end{array}$ & $\begin{array}{c}\text { Multiparous } \\
(\mathrm{n}=16,533)\end{array}$ & $\begin{array}{c}\text { Total } \\
(\mathrm{n}=16,851)\end{array}$ \\
\hline $\begin{array}{l}\text { Morning milk yield }(\mathrm{kg} / \mathrm{d}) \\
\text { Chemical composition }(\%)\end{array}$ & $3.23 \pm 0.060^{\mathrm{b}}$ & $4.01 \pm 0.012^{\mathrm{a}}$ & $4.00 \pm 0.012$ \\
Fat & $2.86 \pm 0.059^{\mathrm{a}}$ & $2.57 \pm 0.007^{\mathrm{b}}$ & $2.58 \pm 0.007$ \\
Protein & $3.14 \pm 0.028^{\mathrm{a}}$ & $2.95 \pm 0.004^{\mathrm{b}}$ & $2.95 \pm 0.004$ \\
Lactose & $4.53 \pm 0.029^{\mathrm{a}}$ & $4.19 \pm 0.004^{\mathrm{b}}$ & $4.19 \pm 0.004$ \\
SNF & $8.54 \pm 0.044^{\mathrm{a}}$ & $8.07 \pm 0.006^{\mathrm{b}}$ & $8.08 \pm 0.006$ \\
TS & $11.10 \pm 0.080^{\mathrm{a}}$ & $10.44 \pm 0.010^{\mathrm{b}}$ & $10.46 \pm 0.010$ \\
Quantity $(\mathrm{g} / \mathrm{d})$ & & & \\
Fat & $90.9 \pm 2.17^{\mathrm{b}}$ & $99.8 \pm 0.33^{\mathrm{a}}$ & $99.7 \pm 0.33$ \\
Protein & $100.6 \pm 1.87^{\mathrm{b}}$ & $116.4 \pm 0.33^{\mathrm{a}}$ & $116.1 \pm 0.33$ \\
Lactose & $146.8 \pm 2.91^{\mathrm{b}}$ & $168.8 \pm 0.53^{\mathrm{a}}$ & $168.4 \pm 0.53$ \\
SNF & $275.3 \pm 5.17^{\mathrm{b}}$ & $322.6 \pm 0.95^{\mathrm{a}}$ & $321.7 \pm 0.94$ \\
TS & $356.6 \pm 6.63^{\mathrm{b}}$ & $415.0 \pm 1.19^{\mathrm{a}}$ & $413.9 \pm 1.18$ \\
\hline
\end{tabular}

${ }_{\mathrm{a}, \mathrm{b}}$ Means within a row with different lowercase superscripts differ $(P<0.001)$.

Based on morning milk yield means, dromedary camels could be divided into 3 milk production categories, such as high (>4.2 kg: Emirati-cross, Black, Pakistani), medium (3.8 to $4 \mathrm{~kg}$ : Emirati, Saudi-cross), and low $(<3.7 \mathrm{~kg}$ : Saudi, Sudanese) producing genotypes (Figure 1). Despite being significant, differences in milk composition among breeds were small and inconsistent. Moderate fluctuations of $6.6,5.9$, and $4.1 \%$ were observed in mean protein, SNF, and TS concentrations, respectively. Whereas, mean fat and lactose levels were markedly different among ecotypes, with differences up to 18.2 and $13.2 \%$, respectively (Figure 1 ). The amount of major milk components changed in parallel with milk production (data not shown).

\section{Effect of Calf Sex}

The effect of sex was tested on 13,854 milk samples. Of these samples, $46.8(\mathrm{n}=6,487)$ and $53.2 \%(\mathrm{n}=$ 7,367 ) originated from dromedaries raising female and male calves, respectively. The mixed linear model showed that sex of the calf influenced milk production and some major milk components. Although statistically significant, these differences are not likely to be of biological importance. Average morning milk produc- tion of animals with male calves $(4.03 \pm 0.007 \mathrm{~kg} / \mathrm{d})$ was higher $(P<0.05)$ than that of dromedaries raising female calves $(3.99 \pm 0.008 \mathrm{~kg} / \mathrm{d})$. By contrast, lactose and SNF concentrations were higher $(P<0.05)$ in milk from dams with female calves $(4.24 \pm 0.004$ and $8.10 \pm 0.004 \%$, respectively) than in milk from dams with male calves $(4.23 \pm 0.004$ and $8.07 \pm 0.004 \%$, respectively). However, no difference was observed $(P>$ $0.05)$ in fat, protein, and TS levels (\%) of milk samples collected from the 2 groups of dromedaries. Similarly, calf sex did not considerably influence the amount of milk components produced, but lactose, SNF, and TS contents tended to be somewhat higher in dromedaries raising male calves.

\section{Effect of Stage of Lactation, Postpartum Changes}

Data on dPP were available for 14,085 samples $(85.2 \%)$ collected from multiparous dromedary camels. Determined by dPP of the last milk sample, the mean length $( \pm \mathrm{SD})$ of lactation was $439 \pm 171 \mathrm{~d}$, but the real length exceeded this. Samples taken after mo 23 of lactation $(>705 \mathrm{dPP})$ were excluded from the analysis. The mixed linear model indicated that the stage of lactation strongly influenced $(P<0.001)$ milk yield

Table 4. Matrix of Pearson correlation coefficients ( $\mathrm{r}$ ) between yield and major chemical composition of morning dromedary camel milk $(\mathrm{n}=16,851)$

\begin{tabular}{lccccrc}
\hline Parameter $^{1}$ & Milk $(\mathrm{kg})$ & Fat $(\%)$ & Protein $(\%)$ & Lactose $(\%)$ & SNF $(\%)$ & TS $(\%)$ \\
\hline Milk (kg) & 1 & -0.252 & -0.251 & 0.116 & -0.083 & -0.204 \\
Fat (\%) & & 1 & 0.703 & -0.111 & 0.346 & 0.861 \\
Protein (\%) & & & 0.128 & 0.747 & 0.846 \\
Lactose (\%) & & & & 0.750 & 0.359 \\
SNF (\%) & & & & 1 & 0.770 \\
TS (\%) & & & & & 1 \\
\hline
\end{tabular}

${ }^{1}$ Significant correlation between all parameters tested $(P<0.001)$. 
and all milk components. However, there was also a significant interaction with season (month of the year, $P<0.001$ ); therefore, the effect of the 2 factors could not be separated.

Mean morning milk yield reached its maximum during mo 4 of lactation at $4.58 \pm 0.01 \mathrm{~kg} / \mathrm{d}$, and then it decreased slowly until mo 8 , followed by a steady decline throughout the long lactation period $(\sim 3.1 \%$ per month) to $2.94 \pm 0.04 \mathrm{~kg} / \mathrm{d}$ at $23 \mathrm{mPP}$. Monthly mean fat, protein, lactose, SNF, and TS concentrations of morning milk showed large fluctuation from 2.0 to $3.8,2.7$ to $3.4,3.6$ to $5.0,7.5$ to 9.1 , and 10 to $11.9 \%$ throughout lactation, respectively (Figure 2).
The concentration of all milk components decreased from 1 to $5 \mathrm{mPP}$, owing to dilution by increasing milk quantity during this period. Later, lactose concentration continued to decrease in parallel with decreasing milk production. However, the concentration of other components showed a temporary increase in mid-lactation, from 6 to $11 \mathrm{mPP}$, and $1 \mathrm{yr}$ later, from 18 to $23 \mathrm{mPP}$, resulting in an overall increasing tendency in fat, protein, and TS concentrations throughout lactation (Figure 2). Changes in quantity of major chemical components of the morning milk showed very different postpartum patterns. Lactose, SNF, and TS content decreased simultaneously with milk yield, whereas total
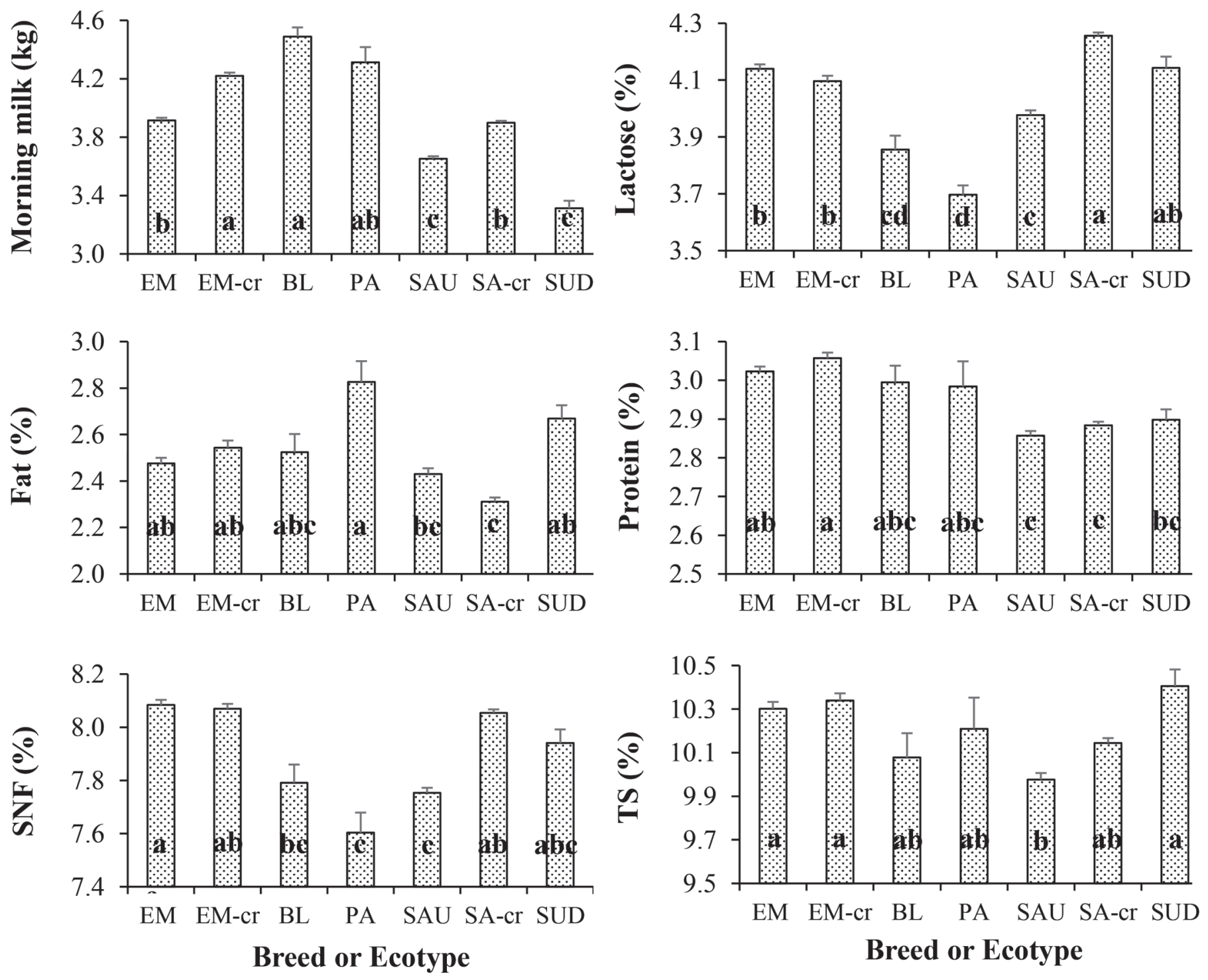

Breed or Ecotype

Figure 1. Influence of breed or ecotype $(\mathrm{EM}=$ Emirati; EM-cr $=$ Emirati-cross; BL = Black; PA = Pakistani; SAU $=$ Saudi; SA-cr $=$ Saudicross; SUD $=$ Sudanese) on mean chemical composition and daily yield of morning dromedary camel milk. Bars with different letters (a-d) differ $(P<0.05)$. Error bars indicate SEM. 
fat production increased from 6 to $11 \mathrm{mPP}$, followed by a 6 -mo decline and an increase again in late lactation. In contrast, protein yield of the morning milk was
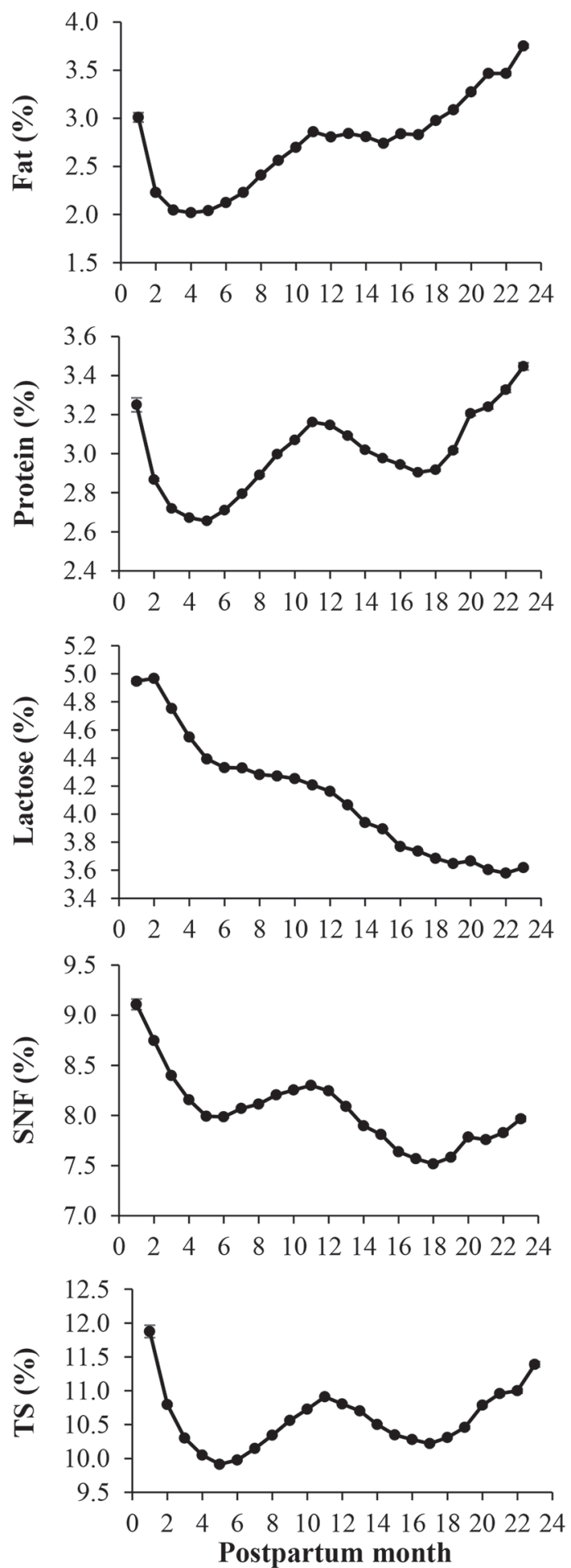

relatively constant for $1 \mathrm{yr}$, but then it dropped sharply by $15 \mathrm{mPP}$ and remained stable at a lower level for the rest of the lactation period (Figure 2).
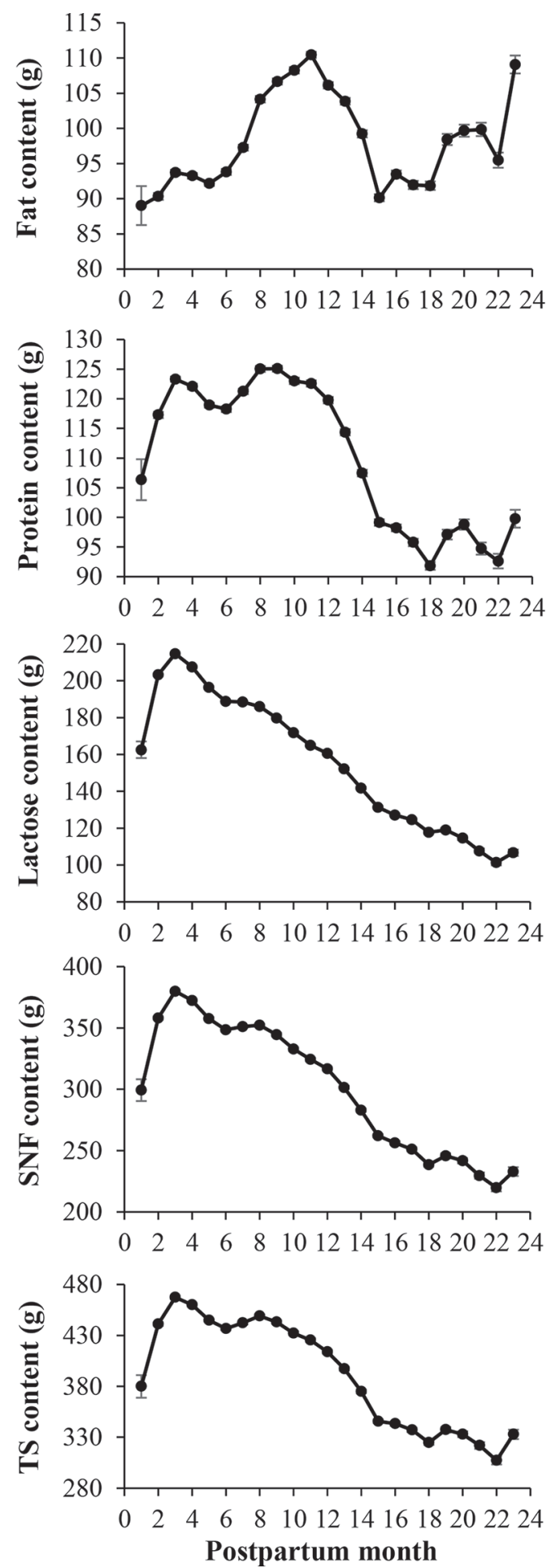

Figure 2. Postpartum changes in monthly mean fat, protein, lactose, SNF, and TS concentrations (\%) and contents (g/d) of morning dromedary camel milk. Error bars indicate SEM. 


\section{Effect of Season, Monthly Changes}

As confirmed by the mixed linear model, month of the year exerted a strong effect $(P<0.001)$ on both the yield and the chemical composition of camel milk. In addition, its interaction with the stage of lactation was also significant $(P<0.001)$. Average morning milk yield was at its lowest $(3.85 \pm 0.02 \mathrm{~kg} / \mathrm{d})$ at the beginning of the year, then it increased gradually until July, and peak production was observed in November $(4.23$ $\pm 0.02 \mathrm{~kg} / \mathrm{d})$. Monthly fluctuations in average milk yield were moderate $(<9 \%)$.

As shown in Figure 3, monthly changes in mean fat, protein, SNF, and TS concentrations (\%) of the morning milk showed the same typical seasonal pattern. The highest values were observed during winter (December and January), whereas the lowest percentages were measured in summer (June and July). At the same time, the lowest mean lactose concentrations were recorded in fall (September and October). The mean fat, protein, lactose, SNF, and TS concentrations ranged from 2.1 to $3.0,2.7$ to $3.3,4.1$ to $4.4,7.8$ to 8.6 , and 9.8 to $11.3 \%$, respectively, throughout the year. The extent of seasonal changes was most pronounced for fat concentration (28.7\%), followed by protein (19.9\%), TS (12.8\%), SNF (9.5\%), and lactose (5.5\%).

As a general rule, changes in mean amounts of fat, protein, SNF, and TS in morning milk followed a seasonal pattern similar to that observed for concentrations. However, SNF and TS contents were not statistically different from January to August and from April to August, respectively. Mean lactose content was relatively stable throughout the year, with 2 peaks in fall corresponding to an increase in average milk yield in September and November (Figure 3).

\section{Effect of Year}

The effect of year was tested on milk samples collected from multiparous dromedaries belonging to the ecotypes Emirati, Emirati-cross, Saudi, and Saudicross. These 4 breeds provided the majority of milk samples evaluated in the present study (Table 1). Milk yield and the concentrations and amounts of all major chemical components in milk varied among the years $(P<0.001)$, with significant interaction between year and genotype $(P<0.001)$. Average concentrations of major milk components were higher during the middle of the study period (2010 to 2012) than in the first and last years (2009 and 2013). The yearly fluctuation in mean fat, protein, lactose, SNF, and TS concentrations was $8.2,8.3,4.1,5.0$, and $4.5 \%$, respectively. The highest quantity of milk components was measured in 2012, corresponding to an increased milk yield in that specific year (data not shown).

\section{DISCUSSION}

Our study is the most comprehensive to date on gross chemical composition of dromedary camel milk under intensive management. It is likely that the number of observations in our research exceeded the combined number of samples from all previously published reports in the international scientific literature. It may also be worth mentioning that most previous studies included animals raised under extensive or semiextensive management or experimental conditions. However, the strength of the present work lies not only in the large number of samples, but also in the stringent control of experimental conditions. We have provided constant management and feeding, standardized sample and data collection, and we have closely controlled the laboratory determination of major milk constituents throughout the 5-yr period of the study. Moreover, because of our specific management practices and conditions, such as constant feeding over the years, long lactation periods $(>440 \mathrm{~d})$, and presence of several breeds or ecotypes at the same location, we were able to make observations that had not been possible in earlier researches. Therefore, we believe that the findings of this work genuinely describe physiological principles and the true role of genetic and nongenetic factors influencing milk composition in this species. In addition, the current paper sheds light on the conflicting results of previous studies dealing with factors of variation of camel milk composition.

The overall mean concentrations of major milk components determined in our study were considerably lower compared with data summarized by Konuspayeva et al. (2009) and Al haj and Al Kanhal (2010). However, the values reported recently by Al-Saiady et al. (2012) and Musaad et al. (2013) are closer to our observations, even though those authors did not clearly define whether their results were obtained from morning or afternoon milk samples. Aljumaah et al. (2012) evaluated milk composition based on samples collected in the afternoon, and the values were higher than ours in the current study. We wish to emphasize that our data were generated from morning milking and, as we showed earlier, the concentrations of solids significantly differ between morning and afternoon milk samples, with fat and TS levels being lower, whereas lactose and SNF were higher in morning milk than in afternoon samples (Nagy et al., 2013b). The notable differences in overall means between our work and previous studies may be due to numerous reasons, such as the number of 
observations (sample size), different environmental and physiological conditions, less stringent control of experimental design, sampling and laboratory methodology, and so on. Therefore, the comparison of numeric values of milk composition from different studies should be done cautiously. Even the comparison of well-detailed
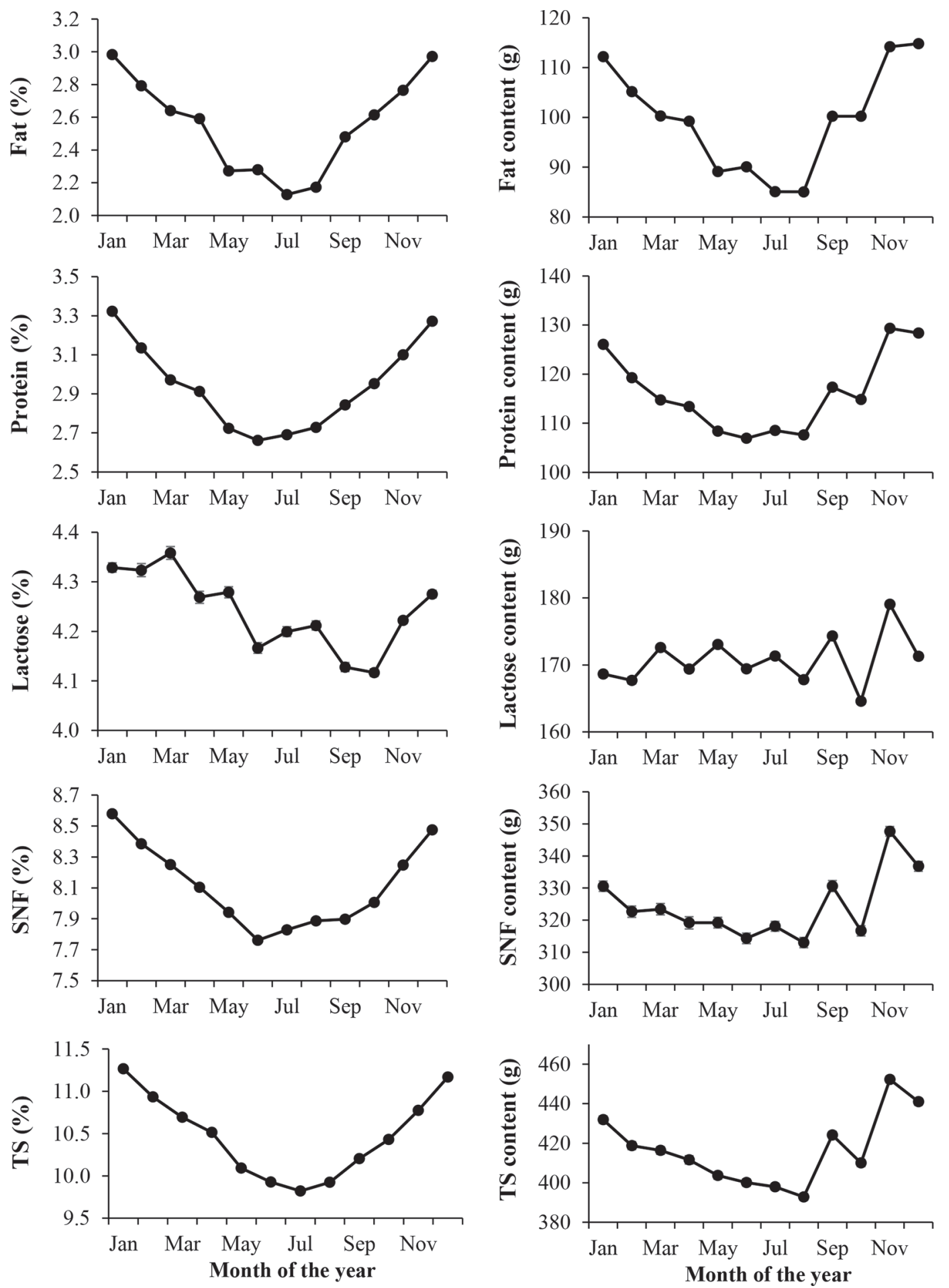

Figure 3. Seasonal changes in monthly mean fat, protein, lactose, SNF, and TS concentrations (\%) and contents (g/d) of morning dromedary camel milk. Error bars indicate SEM. 
reports can be challenging because of different classification (i.e., stages of lactation), management, feeding, statistical methodology, and so on.

As expected, the correlation between milk components, excluding lactose, and milk yield was significantly negative, but the correlation coefficient values suggest that the relationship is rather complex, and an increase or decrease in the percentage of milk solids is not only the consequence of the dilution effect due to the changing milk quantity that had been anticipated earlier. The correlation between most milk constituents was strongly positive; however, unlike Musaad et al. (2013), we found a negative correlation between fat and lactose concentrations.

It is well known among pastoral and nomadic people that the milk of primiparous dromedaries is sweeter and tastes differently compared with the milk of multiparous animals, suggesting different gross chemical composition. Despite the uneven distribution and relatively low number of samples collected from primiparous animals, our results confirmed this age-long practical observation. Markedly increased concentrations of all components were found in the milk of primiparous dromedaries. At the same time, however, the total yield of milk components was reduced as a result of low milk production during the first lactation (Nagy and Juhász, 2016). Surprisingly, none of the previous studies reported such a uniform difference between primi- and multiparous animals. Aljumaah et al. (2012) demonstrated that the highest mean protein, lactose, and SNF levels were measured during the first lactation, and values then decreased from the fourth lactation onward; however, fat composition of camel milk did not change with increasing parity. Bakheit et al. (2008) and Ahmad et al. (2012) also measured the highest protein levels in milk of primiparous dromedary camels and found no effect of parity on fat composition. Lactose, SNF, TS, and ash contents showed diverse patterns with increasing parity. By contrast, Zeleke (2007) demonstrated that milk components reached their peak values during the third lactation and decreased afterward. Finally, some authors found no differences in major milk constituents between primiparous and multiparous dromedaries (Guliye et al., 2000; Al-Sultan and Mohammed, 2007; Musaad et al., 2013).

Our present work confirmed the results of previous studies, demonstrating significant differences in milk composition among dromedary breeds in Saudi Arabia (Mehaia et al., 1995; Gaili et al., 2000; Aljumaah et al., 2012). Nevertheless, general conclusions are difficult to draw because previous studies compared different ecotypes of dromedaries and the results were inconsistent. For example, the only breed (Majaheim) that was evaluated by all authors showed a large variation in milk composition among the reports. Although we found highly significant differences in milk composition of the 7 breeds or ecotypes, these differences, especially in protein, SNF, and TS levels, were not steady and did not appear to be biologically important. We found, however, large variations in mean fat and lactose concentrations among ecotypes. The Pakistani and Saudicross animals had high fat-low lactose $(>2.8 \%,<3.7 \%)$ and low fat-high lactose $(<2.4 \%,>4.2 \%)$ concentrations in their milk, respectively. But this result should be evaluated with caution. Although we controlled for $\mathrm{mPP}$ in our statistical model, it is still possible that this variation is not only the consequence of a genuine breed difference, but also the effect of another factor (e.g., the stage of lactation). In this subset of data, the Pakistani and Saudi-cross dromedaries had the highest (496 d) and lowest $(249 \mathrm{~d})$ mean dPP, respectively. In general, the present study could not convincingly identify a specific genotype that was biologically superior in terms of milk composition to the other breeds or ecotypes. The relatively minor differences in milk composition among the breeds included in our study could be related to the fact that, despite important phenotypic variations among dromedary ecotypes (Abdallah and Faye, 2012), camel genotyping studies revealed low divergence at the DNA level and close genetic distance between breeds in several countries (Al-Swailem et al., 2007; Mahrous et al., 2011). Our study also confirmed previous findings that important differences can be observed in the production potential of various genotypes (Ismail and Al Mutairi, 1998; Gaili et al., 2000). Under our conditions, Black, Pakistani, and Emirati-cross breeds had the highest, whereas Saudi and Sudanese animals had the lowest milk yield. It is interesting to note that milk production potential appears to correlate to morphological characteristics. High-producing breeds have larger body size, BW, and mammary gland than do low-producing ecotypes (Abdallah and Faye, 2012; Nagy and Juhász, 2016).

Ours is the first study that has associated calf sex with milk production and composition of the dam in this species. Earlier, Musaad et al. (2013) evaluated the role of calf and adult weight and gestation length but found no effect on milk composition. We have shown that dromedary camels nursing a male calf produce more milk than do their counterparts with a female calf. Although significant, the difference was rather small because dromedaries with male calves produced $\sim 35 \mathrm{~kg}$ more milk during a 500-d lactation period. Interestingly, the difference in milk composition was female-biased because lactose and SNF concentrations were significantly yet marginally higher in milk from dromedaries raising female calves. No other parameter differed according to the sex of the calf. Sex-dependent 
differences in milk synthesis and composition have been demonstrated in several species. For instance, Holstein cows produce more milk if they have a daughter. By contrast, Iberian red deer dams rearing sons have elevated milk production and total protein yield (Hinde et al., 2014). Such a sex-biased milk synthesis is either the result of in utero programming of mammary function by the offspring or the consequence of postpartum sexbiased nursing behavior. Hinde at al. (2014) provided evidence for the first possibility by demonstrating a long-term physiological effect of the female progeny on milk production of Holstein cows. We can explain our findings using the latter approach. In dromedaries, male calves are born with approximately 3 to $4 \%$ higher BW than female calves (P. Nagy and J. Juhász, unpublished data). It is likely that bigger male calves requiring more milk stimulate the mammary gland more frequently, which results in higher overall milk synthesis without affecting the total quantity of milk components. However, at present no data are available on sex-dependent suckling behavior in dromedary calves to confirm this hypothesis.

Most authors agree that the stage of lactation influences milk composition in this species, and the highest TS levels are measured during the first stage of lactation (Zeleke, 2007; Konuspayeva et al., 2010; Aljumaah et al., 2012; Al-Saiady et al., 2012; Musaad et al., 2013); however, data on the direction of changes later in lactation are equivocal. Zeleke (2007) reported an increase in fat and protein contents following mo 9 of lactation. Aljumaah et al. (2012) and Musaad et al. (2013) confirmed this finding for fat, but they observed a continuous decrease in protein and lactose levels throughout lactation. In contrast, Al-Saiady et al. (2012) showed decreasing fat and increasing protein concentrations toward the end of lactation. To make the picture even more complicated, Guliye et al. (2000) demonstrated no effect of stage of lactation on camel milk composition. Our study not only confirmed previous findings in the sense that it demonstrated the strong influence of stage of lactation, but also provided a detailed description of postpartum changes in concentration and content of major milk components and milk quantity. However, these postpartum patterns differ considerably from earlier findings. Apart from sample size, the difference is due to the definition of stages and length of lactation. In previous reports, milk composition was generally monitored until the end of an approximately 300-d long lactation period, and late stage was defined as $>200 \mathrm{~d}$. By contrast, in the present work, we followed up milk composition for over $700 \mathrm{~d}(23 \mathrm{mo})$ because dromedaries have a long lactation under intensive management (Nagy et al., 2013b). During this long lactation period, animals were fed a constant diet (a steady source of raw material and ration) that allowed us to investigate postpartum and seasonal effects without interference from nutritional factors. We detected a strong interaction between $\mathrm{mPP}$ and month of the year; thus, the effect of the 2 factors could not be separated in our model. Therefore, it is reasonable to assume that the observed patterns of milk components throughout lactation not only reflect postpartum changes in cellular milk synthesis of the mammary gland, but also the effects of seasonal environmental or endogenous factors. This assumption is supported by our finding of temporary increases in fat, protein, SNF, and TS concentrations with synchronized timing (12 mo apart) and the duration (5 to $6 \mathrm{mo}$ ) concomitant to a slow decrease in milk yield. Such a temporary increase in concentrations could partly be the manifestation of seasonal effects on mammary cell function (Casey and Plaut, 2012).

Our study has provided unequivocal evidence that the month of the year (season) exerts a strong influence on the composition of dromedary camel milk. Although some consensus exists on the effect of season, data in the literature are somewhat inconclusive. Various authors reported increases in fat, protein, and TS contents and decreases in lactose levels during winter, from November to February, compared with the summer months (Zeleke, 2007; Haddadin et al., 2008). Shuiep et al. (2008) partly confirmed these results, in that fat and TS increased during winter, but found opposite seasonal changes in protein and lactose contents. Musaad et al. (2013) also reported maximum fat, protein, and lactose concentrations in January and February, whereas minimum values for fat, protein, and lactose were observed during summer and fall, respectively. By contrast, Ahmad et al. (2012) measured the highest fat, protein, and TS contents during the hot, dry summer and rainy season from August to October. Here we demonstrated that the mean concentrations of major milk constituents show an important and orderly seasonal variation, with the lowest and highest values recorded during the summer and winter months, respectively. Interestingly, Heck et al. (2009) described a very similar annual variation (highest to lowest: fat > protein $>$ lactose) in bovine raw milk composition, but concluded that those changes were likely to be of dietary origin because variations coincided with seasonal changes in the average Dutch dairy diet. In our study, as mentioned above, this pattern cannot be explained by nutrition because diet was constant throughout the year. Rather, annual fluctuations in the chemical composition of camel milk could be related partly to seasonal reproduction and also to seasonal changes in environmental factors, such as photoperiod and ambient temperature. Dromedaries are seasonal breeders and most parturitions (70\%) occurred from December 
to March; therefore, newly delivered camels entered milking mainly in late winter and spring.

In the Middle East (latitude $25^{\circ} \mathrm{N}$ ), circannual changes in environmental conditions are moderate compared with continental climate, such as in central Europe (latitude $45^{\circ} \mathrm{N}$ ). The differences in daylight and average daily temperature between the summer and winter periods are only $3 \mathrm{~h}$ and 20 to $25^{\circ} \mathrm{C}$, respectively, on the premises of the farm (Nagy and Juhász, 2012). However, the amplitude of annual changes in fat and protein levels in our study was greater than what had been observed in bovine milk at much higher latitude. Taking into account all the aforementioned information, we hypothesized that seasonal changes in the chemical composition of camel milk may reflect an endogenous circannual biological rhythm with a strong underlying pacemaker that is generated by the circadian system and entrained by environmental cues (Casey and Plaut, 2012; Suárez-Trujillo and Casey, 2016). To support this hypothesis, El Allali et al. (2013) recently demonstrated the existence of an endogenous circadian clock in dromedaries by describing rhythmic daily changes in body temperature under a constant photoperiod and ambient temperature. In addition, an increasing body of evidence suggests that central and peripheral (mammary gland) circadian clocks regulate both the daily and seasonal changes in expression of genes in the mammary gland that are responsible for controlling milk synthesis (Casey and Plaut, 2012; Suárez-Trujillo and Casey, 2016). The positive effect of photoperiod on milk yield has already been demonstrated in several dairy animal species (Dahl et al., 2012), but in vivo data associating circannual changes in milk composition with endogenous rhythms or photoperiod are scarce. Therefore, the dromedary camel, with its lactation stretching over 2 annual cycles, could provide a unique model to study the regulation of mammary cell function by endogenous and environmental factors.

We observed a moderate year-on-year variation in gross chemical composition of camel milk in the present work, namely values in the middle of the study period were higher compared with the first and last year. National statistics showed considerable changes in bovine milk composition over the years that has been cited by several authors and was attributed to different feeding, breeding, and cattle management practices (e.g., milking frequency; Heck et al., 2009; Chen et al., 2014). By analyzing literature data, Konuspayeva et al. (2009) also reported differences in dromedary camel milk composition among the groups of publication years, but those authors explained their findings with changing analytical methods. The interpretation of our results is somewhat difficult because none of the aforementioned reasons are relevant for the present study. We specu- lated that yearly variations in milk composition under our conditions (i.e., constant management) may have resulted from annual changes in intensity of certain environmental factors (e.g., ambient temperature, microclimate, and so on) that may have affected the extent of seasonal changes (amplitude) in chemical composition. To support this assumption, we looked at weather data collected at a nearby meteorological station and found significant yearly variations in daily maximum, minimum, and average ambient temperatures (http:// en.tutiempo.net/climate/12-2013/ws-411940.html).

Interestingly, the mean temperature values were lower in the first and last year than in the middle $3 \mathrm{yr}$ of our study. Although this is a noteworthy observation, it is not sufficient to establish a cause-effect relationship.

\section{CONCLUSIONS}

We monitored gross chemical composition in regularly collected morning milk samples of dromedary camels under intensive management as part of a herd health program for a period of almost $5 \mathrm{yr}$. In general, the mean concentrations of major milk components were considerably lower compared with data published earlier. We concluded that, among the variation factors, parity, stage of lactation, and season exerted the most pronounced effect on milk composition and quantity, but the role of $\mathrm{mPP}$ and month of the year could not be separated in this study. In addition, breed or ecotype and year also influenced all milk quality parameters. However, some of the differences did not appear to be biologically important, and we could not identify a specific breed or ecotype that was superior in terms of milk composition to the other breeds. For the first time, we described significant yet small calf sexbiased differences in milk yield and milk composition in dromedaries. The orderly seasonal variation in fat and protein levels with high amplitude was independent of nutritional factors and may reflect an endogenous circannual rhythm generated by the circadian system. This study shows that the dromedary camel, with its long lactation period, could be a useful in vivo model to study the homeorhetic regulation of mammary cell function by endogenous and environmental factors.

\section{ACKNOWLEDGMENTS}

We thank the staff at Emirates Industry for Camel Milk and Products (EICMP; Dubai, UAE) for the smooth operation of the farm and their commitment to carry out procedures and sample collections precisely. We also express our gratitude to the founder and management of EICMP for supporting our research and development activities in lactating dromedary camels. 
Authors Zsófia Nóra Fábri and László Varga gratefully acknowledge research funding support from the Government of Hungary and the European Union (Project No.: EFOP-3.6.2-16-2017-00012).

\section{REFERENCES}

Abdallah, H. R., and B. Faye. 2012. Phenotypic classification of Saudi Arabian camel (Camelus dromedarius) by their body measurements. Emir. J. Food Agric. 24:272-280.

Abdoun, K. A., A. S. A. Amin, and A. M. Abdelatif. 2007. Milk composition of dromedary camels (Camelus dromedarius): Nutritional effects and correlation to corresponding blood parameters. Pak. J. Biol. Sci. 10:2724-2727. https://doi.org/10.3923/pjbs.2007.2724 2727.

Ahmad, S., M. Yaqoob, M. Q. Bilal, M. K. Khan, G. Muhammad, L. G. Yang, and M. Tariq. 2012. Factors affecting yield and composition of camel milk kept under desert conditions of central Punjab, Pakistan. Trop. Anim. Health Prod. 44:1403-1410. https://doi .org/10.1007/s11250-012-0079-3.

$\mathrm{Al}$ haj, O. A., and H. A. Al Kanhal. 2010. Compositional, technological and nutritional aspects of dromedary camel milk. Int. Dairy J. 20:811-821. https://doi.org/10.1016/j.idairyj.2010.04.003.

Al-Saiady, M. Y., H. H. Mogawer, B. Faye, S. E. Al-Mutairi, M. Bengoumi, A. Musaad, and A. Gar-Elnaby. 2012. Some factors affecting dairy she-camel performance. Emir. J. Food Agric. 24:85-91. https://doi.org/10.9755/ejfa.v24i1.10602.

Al-Sultan, S. I., and A. M. Mohammed. 2007. The effects of the number of lactations on the chemical composition of camel milk. J. Camel Pract. Res. 14:61-63.

Al-Swailem, A. M., K. A. Al-Busadah, M. M. Shehata, I. O. Al-Anazi, and E. Askari. 2007. Classification of Saudi Arabian camel (Camelus dromedarius) subtypes based on RAPD technique. J. Food Agric. Environ. 5:143-148.

Aljumaah, R. S., F. F. Almutairi, E. Ismail, M. A. Alshaikh, A. Sami, and M. Ayadi. 2012. Effects of production system, breed, parity and stage of lactation on milk composition of dromedary camels in Saudi Arabia. J. Anim. Vet. Adv. 11:141-147. https://doi.org/10 .3923/javaa.2012.141.147.

Bakheit, S. A., A. M. A. Majid, and A. M. M. A. Nikhala. 2008 Camels (Camelus dromedarius) under pastoral systems in North Kordofan, Sudan: Seasonal and parity effects on milk composition. J. Camelid Sci. 1:32-36.

Barron, L. J. R., E. F. de Labastida, S. Perea, F. Chávarri, C. de Vega M. S. Vicente, M. I. Torres, A. I. Nájera, M. Virto, A. Santisteban, F. J. Pérez-Elortondo, M. Albisu, J. Salmerón, C. Mendía, P. Torre, F. C. Ibáñez, and M. de Renobales. 2001. Seasonal changes in the composition of bulk raw ewe's milk used for Idiazabal cheese manufacture. Int. Dairy J. 11:771-778. https://doi.org/10.1016/ S0958- 6946(01)00120-0

Casey, T. M., and K. Plaut. 2012. Lactation biology symposium: Circadian clocks as mediators of the homeorhetic response to lactation. J. Anim. Sci. 90:744-754. https://doi.org/10.2527/jas.2011 $-4590$

Chen, B., M. J. Lewis, and A. S. Grandison. 2014. Effect of seasonal variation on the composition and properties of raw milk destined for processing in the UK. Food Chem. 158:216-223. https://doi .org/10.1016/j.foodchem.2014.02.118.

Dahl, G. E., S. Tao, and I. M. Thompson. 2012. Lactation biology symposium: Effects of photoperiod on mammary gland development and lactation. J. Anim. Sci. 90:755-760. https://doi.org/10 $.2527 /$ jas.2011-4630.

El Allali, K., M. R. Achaâban, B. Bothorel, M. Piro, H. Bouâouda, M. El Allouchi, M. Ouassat, A. Malan, and P. Pévet. 2013. Entrainment of the circadian clock by daily ambient temperature cycles in the camel (Camelus dromedarius). Am. J. Physiol. Regul. Integr. Comp. Physiol. 304:R1044-R1052. https://doi.org/10.1152/ ajpregu.00466.2012.
Elamin, F. M., and C. J. Wilcox. 1992. Milk composition of Majaheim camels. J. Dairy Sci. 75:3155-3157. https://doi.org/10.3168/jds .S0022-0302(92)78079-5.

Fábri, Zs. N., L. Varga, and P. Nagy. 2014. Production, general characteristics, chemical composition and health benefits of camel milk. Literature review. 1. Physical and chemical properties, protein and fat contents. Magyar Állatorvosok Lapja 136:485-493. (in Hungarian).

FAO (Food and Agricultural Organization of the United Nations) 2017. FAOSTAT: Live animals. Accessed Feb. 27, 2017. http:// faostat3.fao.org/browse/Q/QA/E.

Faye, B., and P. Bonnet. 2012. Camel sciences and economy in the world: Current situation and perspectives. Pages 2-12 in Proc. 3rd ISOCARD Conf., Muscat, Oman. Sultan Qaboos University Publishing, Muscat, Oman.

Fekadu, B., K. Soryal, S. Zeng, D. Van Hekken, B. Bah, and M. Villaquiran. 2005. Changes in goat milk composition during lactation and their effect on yield and quality of hard and semi-hard cheeses. Small Rumin. Res. 59:55-63. https://doi.org/10.1016/j smallrumres. 2004.12.003.

Gaili, E. S. E., M. M. Al-Eknah, and M. H. Sadek. 2000. Comparative milking performance of three types of Saudi camels (Camelus dromedarius). J. Camel Pract. Res. 7:73-76.

Guliye, A. Y., R. Yagil, and F. D. D. Hovell. 2000. Milk composition of Bedouin camels under semi-nomadic production system. J. Camel Pract. Res. 7:209-212

Haddadin, M. S. Y., S. I. Gammoh, and R. K. Robinson. 2008. Seasona variations in the chemical composition of camel milk in Jordan. J. Dairy Res. 75:8-12. https://doi.org/10.1017/S0022029907002750.

Heck, J. M. L., H. J. F. van Valenberg, J. Dijkstra, and A. C. M. van Hooijdonk. 2009. Seasonal variation in the Dutch bovine raw milk composition. J. Dairy Sci. 92:4745-4755. https://doi.org/10.3168/ jds.2009-2146.

Hinde, K., A. J. Carpenter, J. S. Clay, and B. J. Bradford. 2014. Holsteins favor heifers, not bulls: Biased milk production programmed during pregnancy as a function of fetal sex. PLoS One 9:e86169 https://doi.org/10.1371/journal.pone.0086169.

ICAR (International Committee for Animal Recording). 2017. Certified milk meters for cow. Accessed Feb. 27, 2017. http://www.icar .org/index.php/certifications/icar-certifications-for-milk-meters -for cow-sheep-goats/certified-milk-meters-for-cow/.

Ismail, M. D., and S. E. Al Mutairi. 1998. Milk production potential of dairy camels in northern Saudi Arabia. Pages 35-40 in Proc. Workshop Dromedaries, Camels, Dairy Anim., Nouakchott, Mauritania. CIRAD, Montpelier, France.

Kamphuis, C., B. Dela Rue, S. A. Turner, and S. F. Petch. 2015 Devices used by automated milking systems are similarly accurate in estimating milk yield and in collecting a representative milk sample compared with devices used by farms with conventional milk recording. J. Dairy Sci. 98:3541-3557. https://doi.org/10 $.3168 /$ jds.2014-8714.

Konuspayeva, G., B. Faye, and G. Loiseau. 2009. The composition of camel milk: A meta-analysis of the literature data. J. Food Compos. Anal. 22:95-101. /https://doi.org/10.1016/j.jfca.2008.09.008.

Konuspayeva, G., B. Faye, G. Loiseau, M. Narmuratova, A. Ivashchenko, A. Meldebekova, and S. Davletov. 2010. Physiological change in camel milk composition (Camelus dromedarius) 1. Effect of lactation stage. Trop. Anim. Health Prod. 42:495-499. https://doi .org/10.1007/s11250-009-9449-x.

Kouniba, A., M. Berrada, M. Zahar, and M. Bengoumi. 2005. Composition and heat stability of Moroccan camel milk. J. Camel Pract. Res. 12:105-110.

Mahrous, K. F., H. A. I. Ramadan, S. H. Abdel-Aziem, M. A. E. Mordy, and D. M. Hemdan. 2011. Genetic variations between camel breeds using microsatellite markers and RAPD techniques. J. Appl. Biosci. 39:2635-2646.

Mehaia, M. A., M. A. Hablas, K. M. Abdel-Rahman, and S. A. ElMougy. 1995. Milk composition of Majaheim, Wadah and Hamra camels in Saudi Arabia. Food Chem. 52:115-122. https://doi.org/ 10.1016/0308-8146(94)P4189-M. 
Musaad, A. M., B. Faye, and S. E. Al-Mutairi. 2013. Seasonal and physiological variation of gross composition of camel milk in Saudi Arabia. Emir. J. Food Agric. 25:618-624. https://doi.org/10.9755/ ejfa.v25i8.16095.

Nagy, P., B. Faye, O. Marko, S. Thomas, U. Wernery, and J. Juhász. 2013a. Microbiological quality and somatic cell count in bulk milk of dromedary camels (Camelus dromedarius): Descriptive statistics, correlations, and factors of variation. J. Dairy Sci. 96:56255640. https://doi.org/10.3168/jds.2013-6990.

Nagy, P., and J. Juhász. 2012. Environmental factors affecting reproduction in dromedary camels (Camelus dromedarius). Pages 3-7 in Proc. ICAR 2012 Satellite Mtg. Camelid Reprod., Vancouver, Canada. Camel Reproduction Centre, Dubai, United Arab Emirates.

Nagy, P., and J. Juhász. 2016. Review of present knowledge on machine milking and intensive milk production in dromedary camels and future challenges. Trop. Anim. Health Prod. 48:915-926. / https://doi.org/10.1007/s11250-016-1036-3.

Nagy, P., S. Thomas, O. Markó, and J. Juhász. 2013b. Milk production, raw milk quality and fertility of dromedary camels ( Cam- elus dromedarius) under intensive management. Acta Vet. Hung. 61:71-84. /https://doi.org/10.1556/AVet.2012.051.

Schönfeldt, H. C., N. G. Hall, and L. E. Smit. 2012. The need for country specific composition data on milk. Food Res. Int. 47:207-209. https://doi.org/10.1016/j.foodres.2011.05.018.

Shuiep, E. S., I. E. M. El Zubeir, O. A. O. El Owni, and H. H. Musa. 2008. Influence of season and management on composition of raw camel (Camelus dromedarius) milk in Khartoum State, Sudan. Trop. Subtrop. Agroecosystems 8:101-106.

Suárez-Trujillo, A., and T. M. Casey. 2016. Serotoninergic and circadian systems: Driving mammary gland development and function. Front. Physiol. 7:301. https://doi.org/10.3389/fphys.2016.00301.

Varga, L., J. Süle, and P. Nagy. 2014. Short communication: Viability of culture organisms in honey-enriched acidophilus-bifidusthermophilus (ABT)-type fermented camel milk. J. Dairy Sci. 97:6814-6818. https://doi.org/10.3168/jds.2014-8300.

Zeleke, Z. M. 2007. Non-genetic factors affecting milk yield and milk composition of traditionally managed camels (Camelus dromedarius) in Eastern Ethiopia. Livest. Res. Rural Dev. 19:85. Accessed Feb. 27, 2017. http://www.lrrd.org/lrrd19/6/zele19085.htm. 